\title{
(Ir)Rationality of decisions in business research and practice: introduction to the special issue
}

\author{
Alexander Dilger ${ }^{1}$ - Thomas Gehrig ${ }^{2}$. \\ Marko Sarstedt ${ }^{3}$
}

With this special issue "(Ir)Rationality of decisions in business research and practice," Business Research embarks on a new strategy to publish special issues on cross-over topics of general interest to a large number of subfields in business research. By doing so Business Research closely supports and complements the activities of the German Academic Association for Business Research (VHB) to reintegrate the many diverging subfields of business research on issues of common interest.

The title of this special issue focuses on the implications of (ir)rationality on business research and, hence, is particularly suited to bring together the widely diverging subfields, each of which is affected by the (ir)rationality of its actors. This is why this title has been chosen as the motto of the 2018 Annual Conference in Magdeburg. For the same reason it is the perfect title for the kick-off special issue.

Understanding seemingly irrational behavior is an integral part of business research. According to the traditional paradigm, all human decisions are rational and informed, motivated by an accurate assessment of goods and services' utility. Under this set of assumptions, all actors in the marketplace try to maximize their profit or utility. In contrast, at the intersection of standard economics and behavioral sciences (e.g., behavior economics or consumer psychology), researchers realize that

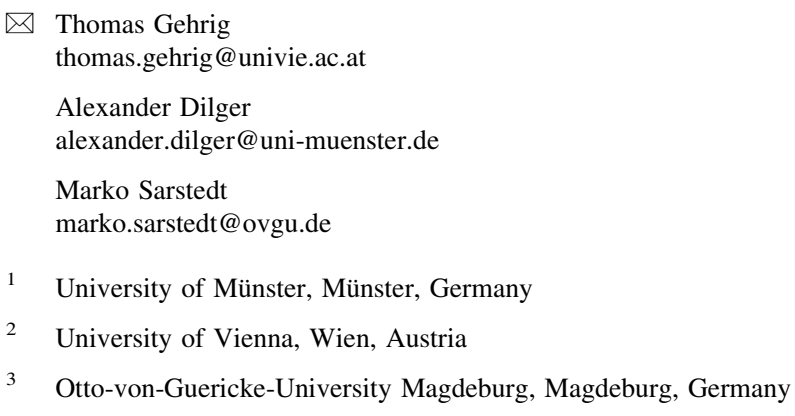


decision-makers are susceptible to contextual influences from their immediate environment (often called context effects), emotions, shortsightedness, and other forms of irrationality (Amir et al. 2005; Ariely 2010). Likewise, seminal work in this field suggest that decision-makers' cognitive capacities are limited, inducing the use of heuristics to simplify choice processes (Gigerenzer and Todd 1999; Goldstein and Gigerenzer 2002; Kahneman et al. 1991; Simon 1982a, 1982b, 1997). As a result, much of everyday decision-making appears irrational (Masicampo and Baumeister 2008; Novemsky et al. 2007).

For example, consumer behavior researchers have long acknowledged that consumers' purchase decisions do not occur in a vacuum, but depend on the context in which they are embedded, such as the composition of a set of products or services (Prelec et al. 1997). The compromise effect, according to which consumers prefer options positioned-as a compromise-in the middle position of a perceived product space to more extreme options, ranks among the most prominent of these context effects (Lichters et al. 2015; Simonson 1989). Numerous studies have shown that adding a high-tier premium option promotes the choice share of a compromise option of medium quality and price compared to that of a low-tier option (e.g., Lichters et al. 2016a, b; Neumann et al. 2016). As such, the compromise effect violates well-known axioms of rational choice theory such as the independence of irrelevant alternatives, the proportionality principle and quite often even the regularity principle.

Researchers have gone great lengths to identify explanations for the compromise effect. For example, consumers' extremeness aversion (e.g., Chernev 2005) or loss aversion (e.g., Ho et al. 2006) have been identified as prominent theoretical accounts of the effect. By choosing the middle option, consumers avoid extreme choices, which could potentially entail lower utility resulting from too high prices or too low quality. Similarly, evidence on excessive information collection can be understood by attempts to ex-post rationalize compromise decisions and to reduce ambiguity (Gehrig et al. 2016). Other theoretical accounts ground the compromise effect in effort justification (Simonson 1989) and consumers' need for uniqueness (Simonson and Nowlis 2000). These accounts help rationalizing consumers' seemingly irrational behavior. The aim of follow-up research is then to entertain a conflict of sometimes divergent explanations to learn about their relative explanatory power and potential blind spots in explanation.

As a consequence, one could be easily tempted to ask whether there is actually something like irrational behavior or whether researchers have simply failed to identify all the relevant boundary conditions that explain specific choices and actions. In either case, consumers rarely act as suggested by the tidy theories of decision-making. The cause for this disparity lies in the conceptual differences between explanation and prediction. Whereas explanation aims to "test or quantify the underlying causal relationship between effects that can be generalized from the sample to the population of interest" (Shmueli et al. 2016, p. 4553), prediction seeks to apply statistical models to data for the purpose of predicting new or future observations. The disparity between researchers' ability to explain phenomena at the conceptual level and the ability to generate predictions at the measurable level results from problems operationalizing theories and constructs into statistical 
models and measurable data (Shmueli 2010). As a consequence, "the practice in applied research of concluding that a model with a higher predictive validity is 'truer,' is not a valid inference" (Hagerty and Srinivasan 1991, p. 84). In fact, numerous studies have shown that a parsimonious but misspecified model provides better predictions than a correctly specified but more complex model (e.g., Dawes and Corrigan 1974). As such, the quest to understanding (ir)rationality has important implications for the research process, such as choosing the appropriate research designs (e.g., lab vs. field experiments; Gneezy 2017) or methods (e.g., causal vs. predictive vs. causal-predictive methods; Shmueli and Koppius 2011).

"(Ir)Rationality of Decisions in Business Research and Practice", the theme of this special issue was also the theme of the 80th Annual Conference of the VHB in Magdeburg 2018. Most of the twelve articles here have been presented there, either as invited lectures or in the conference's competitive sessions. The articles take various perspectives to shed light on the tradeoff between the rationality-as assumed by optimization techniques and theories on decision-making-and the limited rationality that characterizes human behavior.

The first article titled "C. Y. A.: Frequency and causes of defensive decisions in public administration" by Florian Artinger, Sabrina Artinger, and Gerd Gigerenzer deals with decisions in which a manager ranks an option as the best for the organization yet deliberately chooses a second-best option that protects him- or herself against negative consequences - a concept vividly called "cover your ass" (hence, C. Y. A). The authors' analysis of data from 950 managers in a public administration shows that such defensive decision-making is widespread across all hierarchy levels. Based on their findings, the authors suggest creating a constructive approach to failure and encouraging voice to help lowering the impact of defensive decision-making in an organization.

In the next article titled "The St. Petersburg Paradox despite risk-seeking preferences: An experimental study," James C. Cox, Eike B. Kroll, Marcel Lichters, Vjollca Sadiraja, and Bodo Vogt shed new light on one of the most famous economic and philosophical puzzles that has attracted considerable research interest and is subject to numerous conflicting explanations (e.g., Hayden and Platt 2009). The authors add to this stream of research by providing experimental evidence showing similar play in finite St. Petersburg games with conventional positive prices and negative prices. Their findings are incompatible with the principle of loss aversion and will likely spark follow-up research on the invariance of choices to the sign of prizes.

Ernan Haruvy, Elena Katok, Zhongwen Ma, and Sureshi P. Sethi's article deals with a major pitfall in supply chain management, which has adverse consequences for relationship-specific investments - the hold-up problem. The hold-up problem emerges when one firm in a relationship is able to expropriate the returns from an investment made by another firm. In their article "Relationship-specific investment and hold-up problems in supply chains: Theory and experiments," the authors model the phenomenon as a sequential move game with asymmetric information and derive a model that considers social preferences and reputation. The results suggest that the hold-up problem can be effectively mitigated in settings in which the relationship is not one-shot by means of a reputation mechanism. 
In the fourth article titled "Horizontal monitoring in Austria: Subjective representations by tax officials and company employees," Janina Enachescu, Maximilian Zieser, Eva Hofmann, and Erich Kirchler investigate how the implementation of horizontal monitoring (i.e., moving from a hierarchical to a collaborative relationship between taxpayers and tax authorities) is perceived by different stakeholder groups. Results from a large-scale survey suggest that tax officials involved in horizontal monitoring and participating companies view horizontal monitoring very favorably, whereas this is not the case with stakeholders not directly involved in the process. The authors argue that acceptance or resistance regarding the paradigm change represented by horizontal monitoring may originate from uncertainty and misperceptions of its goals and strategies as well as from speculations particularly by poorly informed members.

John Asmus Christensen's article titled "Corporate choice and individual values: Using accounting to align incentives" discusses how management accounting systems help aligning incentives among those involved in corporate choices. Based on an extensive review of the transfer price literature, the author argues that the accrual accounting system is best suited for aligning incentives.

The sixth article "Partial least squares structural equation modeling-based discrete choice modeling: An illustration in modeling Retailer choice" by Joseph F. Hair, Christian M. Ringle, Siegfried P. Gudergan, Andreas Fischer, Christian Nitzl, and Con Menictas illustrates how the results of choice experiments can be assessed in a wider nomological network. Specifically, the authors show how to merge partial least squares structural equation modeling (PLS-SEM) with discrete choice modeling. PLS-SEM has gained massive dissemination in business research and beyond to model linear relationships among latent and manifest variables (Hair et al. 2019b; Khan et al. 2019; Ringle et al. 2019). As the method estimates the parameters of a model, which is grounded in well-developed causal explanations, by maximizing the amount of explained variance of the dependent latent variables, it bridges the apparent dichotomy between explanation and prediction (Hair et al. 2019a; Shmueli et al. 2019). The authors offer clear guidelines how to reap the method's benefits in a discrete choice modeling framework.

In their article "Big data analytics in sustainability reports: An analysis based on the perceived credibility of corporate published information," Jonas Wanner and Christian Janiesch address a credibility gap in sustainability reports due to information asymmetries but also bounded rationality by the readers of such reports. The authors use qualitative and quantitative surveys of IT- and data-affine experts to find out how big data analytics can improve the credibility of such reports. Using PLS-SEM, the authors show that higher volumes and accuracy of data have a positive effect while a higher variety and velocity of data generation have not.

The eight article "Making regulation fit by taking irrationality into account: The case of the whistleblower" by Sebastian Oelrich uses the prospect theory to explain student behavior in experiments with a whistleblowing scenario. In cases of high ambiguity the participants fear losses more than they are motivated by potential gains. The author concludes that the protection of whistleblowers is more important than to offer positive incentives to uncover fraud and other crimes. 
Thomas Kourouxous and Thomas Bauer look in their article titled "Violations of dominance: A review" at the literature and evidence regarding such violations. Rational decision-makers should always prefer a dominant alternative to a dominated one. However, different kinds of dominance violations can be observed for different reasons. The authors also analyze other paradoxes of choice where less of a good thing is perceived as better than more or a peak-end is preferred to a similar situation followed by something also valuable but less great than the peakend. These kinds of behaviors are not totally irrational but can be explained as bounded rational in a wider sense including emotions.

The tenth article "Price limits under incomplete preference information based on almost stochastic dominance" by Hermann Jahnke, Jan Thomas Martini, and Tobias Wiens models uncertainty about the preferences or utility of a decision-maker (or the principal of an agent acting in his or her not perfectly known interest). Specifically, the authors model a firm selling a good or service with no or incomplete information of its own utility. The concept of almost stochastic dominance helps to find price limits and the firms sells above them. The more information there is, the better these price limits can be adjusted.

In their article "Modeling rational decisions in ambiguous situations: A multivalued logic approach," Olga Metzger and Thomas Spengler apply intuitionistic fuzzy logic to model decisions in ambiguous situations in which the decisionmakers do not know their exact utilities of possible outcomes. Their approach makes an important contribution to the literature by combining core elements of established approaches for the formal handling of uncertainty (maxmin and $\alpha$ maxmin expected utility models) with the mathematical foundation of intuitionistic fuzzy theory.

Christian Julmi analyses intuitive decision-making in the twelfth and last article titled "When rational decision making becomes irrational: A critical assessment and reconceptualization of intuition effectiveness." Intuitive decision-making can have better results than rational analysis under certain circumstances. The author conceptualizes intuition as a holistic form of information processing that is best suited to decision problems of high equivocality, not uncertainty.

To sum up, there are many different approaches to rational, irrational, and especially bounded rational decision-making in this special issue as this is a wide and seminal research field of also high practical importance. We hope that the articles in this special issue will attract attention and will trigger follow-up research.

We thank the staff and board of the VHB as well as the many reviewers without whom this special issue would not have been possible.

Open Access This article is distributed under the terms of the Creative Commons Attribution 4.0 International License (http://creativecommons.org/licenses/by/4.0/), which permits unrestricted use, distribution, and reproduction in any medium, provided you give appropriate credit to the original author(s) and the source, provide a link to the Creative Commons license, and indicate if changes were made. 


\section{References}

Amir, On, Dan Ariely, Alan Cooke, David Dunning, Nicholas Epley, Uri Gneezy, Botond Koszegi, Donald Lichtenstein, Nina Mazar, Sendhil Mullainathan, Drazen Prelec, Eldar Shafir, and Jose Silva. 2005. Psychology, behavioral economics, and public policy. Marketing Letters 16 (3-4): 443-454.

Ariely, D. 2010. Predictably irrational, revised and expanded edition: The hidden forces that shape our decisions, 2nd ed. New York: Harper Perennial-HarperCollins Publishers Inc.

Chernev, Alexander. 2005. Context effects without a context: Attribute balance as a reason for choice. Journal of Consumer Research 32 (2): 213-223.

Dawes, Robyn M., and Bernard Corrigan. 1974. Linear models in decision making. Psychological Bulletin 81 (2): 95-106.

Gehrig, Thomas, Werner Güth, and René Levínský. 2016. On the value of transparency and information acquisition in bargaining. German Economic Review: Special Issue in Honor of Reinhard Selten's 85th Birthday 17 (3): 337-358.

Gigerenzer, Gerd, and Peter M. Todd. 1999. Simple heuristics that make us smart: Evolution and cognition. New York: Oxford University Press.

Gneezy, Ayelet. 2017. Field experimentation in marketing research. Journal of Marketing Research 54 (1): $140-143$.

Goldstein, Daniel G., and Gerd Gigerenzer. 2002. Models of ecological rationality: The recognition heuristic. Psychological Review 109 (1): 75-90.

Hair, Joe F., Jeff J. Risher, Marko Sarstedt, and Christian M. Ringle. 2019a. When to use and how to report the results of PLS-SEM. European Business Review 31 (1): 2-24.

Hair, Joe F., Marko Sarstedt, and Christian M. Ringle. 2019b. Rethinking some of the rethinking of partial least. European Journal of Marketing (forthcoming).

Hagerty, Michael R., and V. Srinivasan. 1991. Comparing the predictive powers of alternative multiple regression models. Psychometrika 56 (1): 77-85.

Hayden, Benjamin Y., and Michael L. Platt. 2009. The mean, the median, and the St. Petersburg paradox. Judgment Decision Making 4 (4): 256-272.

Ho, Teck H., Noah Lim, and Colin F. Camerer. 2006. Modeling the psychology of consumer and firm behavior with behavioral economics. Journal of Marketing Research 43 (3): 307-331.

Kahneman, Daniel, Jack L. Knetsch, and Richard H. Thaler. 1991. Anomalies: The endowment effect, loss aversion, and status quo bias. Journal of Economic Perspectives 5 (1): 193-206.

Khan, Gohar F., Marko Sarstedt, Wen-Lung Shiau, Joe F. Hair, Christian M. Ringle, and Martin P. Fritze. 2019. Methodological research on partial least squares structural equation modeling (PLS-SEM): An analysis based on social network approaches. Internet Research (forthcoming).

Lichters, Marcel, Marko Sarstedt, and Bodo Vogt. 2015. On the practical relevance of the attraction effect: A cautionary note and guidelines for context effect experiments. AMS Review 5 (1-2): 1-19.

Lichters, Marcel, Claudia Brunnlieb, Gideon Nave, Marko Sarstedt, and Bodo Vogt. 2016a. The influence of serotonin deficiency on choice deferral and the compromise effect. Journal of Marketing Research 53 (2): 183-198.

Lichters, Marcel, Holger Müller, Marko Sarstedt, and Bodo Vogt. 2016b. How durable are compromise effects? Journal of Business Research 69 (10): 4056-4064.

Masicampo, Emer J., and Roy F. Baumeister. 2008. Toward a physiology of dual-process reasoning and judgment: Lemonade, willpower, and expensive rule-based analysis. Psychological Science 19 (3): $255-260$.

Neumann, Nico, Ulf Böckenholt, and Ashish Sinha. 2016. A meta-analysis of extremeness aversion. Journal of Consumer Psychology 26 (2): 193-212.

Novemsky, Nathan, Ravi Dhar, Norbert Schwarz, and Itamar Simonson. 2007. Preference fluency in choice. Journal of Marketing Research 44 (3): 347-356.

Prelec, Drazen, Birger Wernerfelt, and Florian Zettelmeyer. 1997. The role of inference in context effects: Inferring what you want from what is available. Journal of Consumer Research 24 (1): $118-126$.

Ringle, Christian M., Marko Sarstedt, Rebecca Mitchell, and Siegfried P. Gudergan. 2019. Partial least squares structural equation modeling in HRM research. International Journal of Human Resource Management (forthcoming).

Shmueli, Galit. 2010. To explain or to predict? Statistical Science 25 (3): 289-310. 
Shmueli, Galit, and Otto R. Koppius. 2011. Predictive analytics in information systems research. Management Information Systems Quarterly 35 (3): 553-572.

Shmueli, Galit, Soumya Ray, Juan M. Velasquez Estrada, and Suneel B. Chatla. 2016. The elephant in the room: Evaluating the predictive performance of PLS models. Journal of Business Research 69 (10): 4552-4564.

Shmueli, Galit, Marko Sarstedt, Joe F. Hair, Jun Hwa Cheah, Hiram Ting, and Christian M. Ringle. 2019. Predictive model assessment in PLS-SEM: Guidelines for using PLSpredict. European Journal of Marketing (forthcoming).

Simon, Herbert A. 1982a. Models of bounded rationality. Volume 1: Economic analysis and public policy. Cambridge (Mass.): MIT Press.

Simon, Herbert A. 1982b. Models of bounded rationality. Volume 2: Behavioural economics and business organization. Cambridge (Mass.): MIT Press.

Simon, Herbert A. 1997. Models of bounded rationality. Volume 3: Empirically grounded economic reason, 3rd ed. Cambridge (Mass.), London: MIT Press.

Simonson, Itamar. 1989. Choice based on reasons: The case of attraction and compromise effects. Journal of Consumer Research 16 (2): 158-174.

Simonson, Itamar, and Stephen M. Nowlis. 2000. The role of explanations and need for uniqueness in consumer decision making: Unconventional choices based on reasons. Journal of Consumer Research 27 (1): 49-68.

Publisher's Note Springer Nature remains neutral with regard to jurisdictional claims in published maps and institutional affiliations. 